\title{
A guitarra elétrica no choro: uma análise de Odeon de Ernesto Nazareth na gravação de Olmir Stocker (Alemão)
}

\author{
Eduardo de Lima Visconti (UNICAMP, Campinas, SP) \\ eduvisconti@yahoo.com.br
}

\begin{abstract}
Resumo: Este artigo pretende investigar como Olmir Stocker (Alemão) realiza uma adaptação da linguagem do choro para a guitarra elétrica através da transcrição e análise do contraponto presente na faixa Odeon, gravada em seu disco De $A$ a $Z$ no ano de 1995. Com base na definição de gênero de Franco FABBRI (1982), verifica-se até que ponto o músico imprime inovações que não descaracterizam o choro e, com isso, contribui para o desenvolvimento de uma linguagem brasileira para a guitarra elétrica a partir de um gênero reconhecido como símbolo de brasilidade.
\end{abstract}

Palavras-chave: Arranjo de Olmir Stocker (Alemão); Odeon de Ernesto Nazareth; guitarra elétrica no Brasil e no choro.

\section{Electric guitar in the Brazilian choro: an analysis of Odeon by Ernesto Nazareth as recorded by Olmir Stocker (Alemão)}

\begin{abstract}
This article intends to investigate how Olmir Stocker (Alemão) adapts the choro language to the electric guitar. We transcribe and analyze the counterpoint present on the track Odeon, recorded on his album De $A a Z$ in 1995. Based on the definition of the musical genre put forth by Franco FABBRI (1982), we verify the degree to which the musician pushes for innovations that do not cause the choro to lose its distinctive character, thus contributing to the development of a Brazilian language for the electric guitar based on a genre recognized as a symbol of Brazilianness.
\end{abstract}

Keywords: Arrangement by Olmir Stocker (Alemão); Odeon by Ernesto Nazareth; electric guitar in Brazil and choro.

\section{1 - Introdução: a guitarra elétrica na música popular brasileira}

A guitarra elétrica surgiu nos Estados Unidos no início do século XX como um desdobramento do violão. Os primeiros modelos do instrumento não dispunham de captação elétrica, o que fez com que a empresa Gibson desenvolvesse a primeira guitarra acústica com um captador eletromagnético e a lançasse no mercado no ano de 1935 com o nome de Gibson ES-150. (COOK, 1999). Uma das causas principais para o desenvolvimento de uma amplificação sonora para a guitarra decorreu em virtude da necessidade de aumento de volume dos acompanhamentos feitos por guitarristas das orquestras americanas do swing. A captação permitiu também, um desenvolvimento das possibilidades de improvisação melódica no instrumento elevando-o a um instrumento solista. (COOK, 1999, p.12)
No Brasil, a guitarra elétrica foi introduzida no final da década de 1940 e sua inserção na música popular brasileira foi acompanhada de discursos de rejeição e veneração por parte de críticos e músicos. Identificada como instrumento dotado de dispositivos artificiais (captadores eletrônicos) e portadora de uma carga de significados associados ao jazz e à música pop anglo-americana, a guitarra foi repudiada por uns como símbolo de "estrangeirismo" ou até mesmo do imperialismo cultural sobre a nação brasileira, e reconhecida por outros como elemento de sofisticação e de modernidade musical (VISCONTI, 2010). Em minha tese de doutorado verifiquei alguns conflitos presentes na adaptação desse instrumento no Brasil, que são constitutivos do que chamei de duas narrativas da sua inserção no país (VISCONTI, 2010, p.43).

A primeira está relacionada ao processo de eletrificação da guitarra e seu aparecimento como um instrumento 
vinculado à tecnologia, o que estimulou a reação de algumas pessoas que questionaram sua autenticidade, como também ocorreu nos Estados Unidos. Alguns músicos como José Menezes e Bola Sete, que tocavam outros instrumentos de corda como bandolim, cavaquinho e violão, passaram a incorporar a guitarra elétrica em seu repertório, e fizeram uma adaptação da técnica desses instrumentos para a guitarra, com destaque para a técnica do violão, o que fez com que os limites idiomáticos entre o violão e a guitarra permanecessem indefinidos até 0 final dos anos 1950. Em minhas pesquisas, a presença do violão elétrico em várias gravações da década de 1950 revela que esse instrumento teve uma posição intermediária entre o violão acústico com cordas de nylon e a guitarra, e que sua forma de tocar ilustra a imbricação de técnicas entre esses instrumentos.

A segunda narrativa foi formada em função de uma possivel necessidade de apropriação e reinvenção da guitarra elétrica no país, devido à sua vinculação direta com sua origem norte-americana. Enquanto o processo de consagração do violão como expressão nacional se deu num campo simbólico entre o erudito e popular (NAVES, 1998), a guitarra elétrica parece se inserir na música popular brasileira dentro da polarização da relação entre o nacional e o internacional. Sua origem e identificação com a música norte-americana vão estimular relatos, por parte de alguns músicos, nos quais se verifica a intenção de "nacionalizar" a guitarra/violão elétrico. Essa "necessidade" de abrasileiramento do instrumento fez com que, a partir dos anos 1960, alguns guitarristas como Olmir Stocker (Alemão), o pernambucano Heraldo do Monte (VISCONTI, 2005) e o carioca Hélio Delmiro, entre outros, realizassem adaptações de elementos musicais característicos de alguns gêneros brasileiros para o instrumento numa tentativa de reinventar a guitarra elétrica no Brasil, período que classifico como da consolidação desse instrumento em nossa música popular. ${ }^{1}$

No caso específico do estilo do guitarrista Alemão, sua discografia autoral é baseada em uma diversidade significativa de gêneros regionais e urbanos brasileiros, o que demonstra um conhecimento profundo dessas linguagens musicais e sua adaptação para a guitarra.

\section{2 - Síntese da trajetória do guitarrista Alemão}

Olmir Stocker, conhecido pelo apelido de Alemão, nasceu em 1936 na cidade de Taquari, no Rio Grande do Sul. Começou a se apresentar profissionalmente ainda criança tocando cavaquinho e violão em espetáculos circenses. Aos 18 anos serviu o exército e tomou contato com a guitarra elétrica e, em 1956, se mudou para Porto Alegre. $\mathrm{Na}$ capital gaúcha foi contratado para trabalhar no rádio e atuou ao lado de cantores internacionais e nacionais.

No ano de 1958 foi para Curitiba, onde fez parte do quinteto do acordeonista Breno Sauer como guitarrista. Gravou seis discos com esse conjunto e fez shows pelo Brasil inteiro. No início da década de 1960 viaja para São Paulo, onde foi convidado para participar do conjunto Os Wandecos, que acompanhava a cantora Wanderléa da Jovem Guarda.

Com sua fixação na capital paulista, Alemão atuou na noite paulistana tocando música instrumental em conjuntos de boate e se apresentando com músicos da Jovem Guarda. Em 1967, sua composição "0 Caderninho" foi gravada por Erasmo Carlos e obteve grande sucesso de vendas. Nessa época, o guitarrista também participou dos festivais da Record como compositor e instrumentista.

No ano de 1968 integrou o conjunto Brazilian Octopus num projeto chamado Momento 68, patrocinado pela empresa Rodhia. Esse grupo era formado por vários músicos, entre eles, Hermeto Paschoal, que tinha participado do Quarteto Novo, e o guitarrista Lanny Gordin, que gravou discos com Caetano Veloso, Gal Costa e Maria Bethânia.

A partir de 1970 e 1980, Alemão começa a desenvolver projetos autorais de música instrumental e em 1981, lançou seu primeiro disco pelo selo Som da Gente, intitulado Longe dos olhos perto do coração, que vendeu aproximadamente 30.000 cópias. Em 1987, o guitarrista gravou o disco Alemão Bem Brasileiro e em 1990, Só Sabor. Em 1991, formou um duo com o violonista Zezo Ribeiro e lançou os discos Brasil Geral (1992) e De A a Z (1995).

Em toda sua carreira acompanhou mais de noventa artistas, dentre eles, Gregório Barrios, Ângela Maria, Nelson Ned, Simone, Elis Regina entre outros, e possui em seu arquivo particular mais de 1000 composições próprias.

Alemão fez parte de uma geração de músicos que contribuiu para a consolidação da guitarra elétrica na música popular brasileira. Seu estilo como guitarrista se mostra mais definido a partir da década de 1980, com o início da gravação de seus discos autorais de música instrumental. Nessa produção, verifica-se uma fusão entre a assimilação e abrasileiramento das técnicas da guitarra do jazz, principalmente dos estilos de George Van Eps e Barney Kessel, com matrizes dos gêneros brasileiros, o que aponta para uma nova forma para se tocar e compor música brasileira no instrumento. Como a guitarra elétrica é a base para a execução e feitura de suas composições, pode-se observar a criação e o desenvolvimento pioneiro de um repertório idiomático para o instrumento baseado num amplo leque de gêneros como choro, samba, bossa nova, frevo, toada, chamamé, baião, xote, dentre outros.

A escolha para a análise da guitarra elétrica no choro ${ }^{2}$ Odeon foi feita devido ao fato desse gênero representar, até os dias de hoje, uma forte expressão de brasilidade. Como mostra o pesquisador Dmtri FERNANDES (2010) o choro, conjuntamente com o samba, foi, desde o início do século $X X$, um gênero identificado como portador de elementos da nossa identidade nacional por diversos músicos, críticos e jornalistas como Mário de Andrade, Villa-Lobos, Orestes Barbosa, Vagalume (Francisco 
Guimarães) e Animal (Alexandre Pinto). Para o autor, esses agentes mediadores forneceram contribuições relevantes para o reconhecimento do choro como gênero nacional.

\section{3 - Análise de Odeon na versão de Alemão}

Odeon foi gravada pelo duo formado pelo guitarrista Alemão e o violonista Zezo Ribeiro e integra o disco De $A$ $a Z$, lançado no ano de 1995. Nessa faixa, Alemão toca a guitarra elétrica como um instrumento contrapontístico ao violão num choro, situação pouco encontrada na discografia do instrumento. $\mathrm{Na}$ história do choro, essa função foi muito desenvolvida pelo saxofone de Pixinguinha $^{3}$, sendo que as gravações com Benedito Lacerda são exemplos relevantes de suas improvisações em contraponto a uma melodia. Um dos motivos para a escolha da análise desta regravação de Odeon foi perceber a relação entre preservação e inovação, que o guitarrista pretende atribuir ao gênero do choro.

Segundo o texto da introdução de seu método sobre guitarra elétrica na música brasileira (1999), Alemão afirma que para se tocar música brasileira é necessário que 0 estudante execute suas características melódicas, ritmicas e harmônicas com "sotaque brasileiro", e isso independe do instrumento. Seu argumento pode ser entendido como uma resposta à resistência de alguns "tradicionalistas" ao emprego da guitarra elétrica na música brasileira.

Percebe-se neste texto a dificuldade que a guitarra elétrica ainda se encontra para fugir à sua identificação com a cultura norte-americana e o esforço que o músico tem feito nesse sentido. A possivel intenção do instrumentista ao regravar Odeon é almejar que a guitarra elétrica, instrumento pouco presente nas gravações de choro, possa ser compreendida também dentro desse universo. Contribuindo à sua maneira para uma inovação da instrumentação mais comum da performance do choro consolidada pelos grupos regionais, bem como, para apreender as estruturas musicais desse gênero nacional e traduzi-las para a guitarra elétrica, depurando uma linguagem brasileira para o instrumento.

No livro Choro do quintal ao municipal de Henrique CAZES (1999) há uma carta do renomado maestro Gaya, publicada em jornais em virtude dos festivais de choro realizados no final da década de 1980.0 maestro aborda a situação que o gênero se encontrava no Brasil e é enfático ao declarar que:

\footnotetext{
Creio que já é hora de se saber e divulgar as bases fundamentais do choro. Não é um violão de sete cordas, pandeiro ou cavaquinho que Ihe dão autenticidade. Uma BOA guitarra elétrica pode tocar um choro melhor do que um MAU violão de sete cordas (CAZES, 1999, p.156).
}

A posição de Alemão se mostra coerente com a posição do maestro, que parece integrar o grupo de músicos que defendem a "inovação" do gênero. Gaya não é rígido quanto ao uso de instrumentos que não se identificam com a sonoridade original da instrumentação "tradicional" do choro, posição coerente com sua postura favorável em relação à modernização do samba verificada pela pesquisadora Joana SARAIVA (2007).

A relação entre preservação e inovação no choro pode ser aprofundada tendo como base o conceito de FABBRI (1982) sobre gênero que, de acordo com sua definição, corresponde a um conjunto de eventos musicais cujo curso é governado por um conjunto definido de regras socialmente aceitas. No choro é preciso investigar se as inovações promovidas por instrumentistas contemporâneos descaracterizam o gênero, ou se elas podem ser entendidas como "regras socialmente aceitas" no momento presente. Nesse caso, a noção de gênero pode ser reconhecida como noção em disputa, pois as "regras socialmente aceitas", constitutivas dos gêneros, são mutáveis e históricas, pois mudam em função de lutas simbólicas que prevalecem em determinados contextos históricos.

Com a transcrição e análise dessa gravação pretendese descobrir quais caminhos que o guitarrista seguiu para executar sua improvisação em contraponto à melodia principal, e se existe alguma similaridade com os contrapontos de Pixinguinha, reconhecidos como referência de uma prática sedimentada no choro. Como suporte teórico para essa verificação foi utilizado a dissertação de mestrado Contracantos de Pixinguinha: contribuições históricas e analíticas para a caracterização do estilo, de Alexandre CALDI (2001) e as transcrições de algumas gravações de Pixinguinha com Benedito Lacerda, organizada por Mário SĖVE e David GANC (2010) em Choro Duetos Vol.1

A guitarra acústica utilizada na gravação é um modelo Gibson 175, o principal instrumento de Alemão até os dias de hoje. Esse modelo foi um dos tipos de guitarra acústica mais usado pelos guitarristas de jazz de diferentes épocas como Wes Montgomery, Herb Ellis, Joe Pass, Howard Roberts e Pat Metheny. Trata-se de um instrumento que, além de ter uma caixa acústica grande e larga, é conhecido pelo seu timbre grave. Alemão faz uma adaptação da sonoridade desse instrumento na música popular brasileira com uma equalização mais aguda e com pouco uso de reverb, o que resulta numa sustentação menor do som compativel com sua técnica de palhetar boa parte das notas e utilizar poucos ligados na mão esquerda, se comparado a alguns guitarristas de jazz como Wes Montgomery e Joe Pass. Um dos elementos constitutivos do seu estilo é a técnica apurada de palhetada alternada da mão direita, que é executada com força e precisão.

A forma da música gravada pelo guitarrista possui sinais de inovação, pois no registro a música é tocada na forma $A A^{\prime}$ BB' A"A"' CC' C"C'" A"'" (a parte A"'" não foi transcrita na partitura), ou seja, cada seção é variada na sua repetição com uma parte A conclusiva com andamento acelerado no final. Essa forma é diferente da sequência mais comum no choro que é AA BB A CC A (SĖVE, 1999, p.19). 
A base da música talvez seja o único elemento recorrente na linguagem do choro, pois o violão toca os acordes junto com a melodia numa maneira próxima à execução original do piano. A melodia principal foi escrita na partitura apenas para facilitar o acompanhamento da gravação, sendo que a linha do violão, que executa esta parte, não foi transcrita.
Foram escolhidos seis exemplos musicais da transcrição de Odeon, que esclarecem o processo de adaptação da linguagem do choro para a guitarra elétrica. A transcrição quase completa (exceto que pela última parte da forma - a seção A"''), realizada por Rodrigo Vicente e revisada pelo autor do presente artigo, se encontra publicada após esse artigo, às p.136-144 desse número de Per Musi.

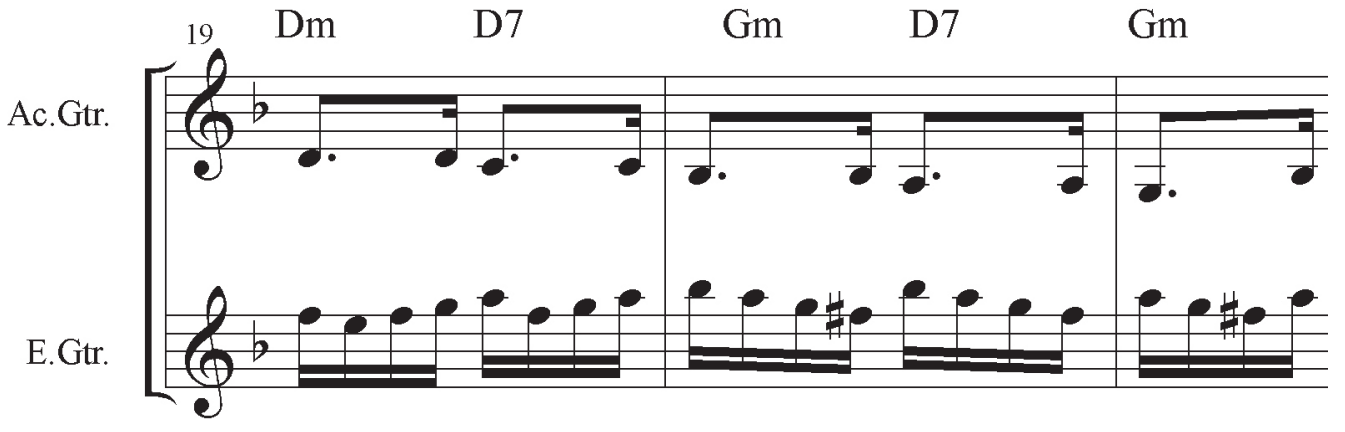

Ex.1 - Ocorrência de padrões melódicos em graus conjuntos em Odeon (Ernesto Nazareth) na gravação de Alemão e Zezo Ribeiro.

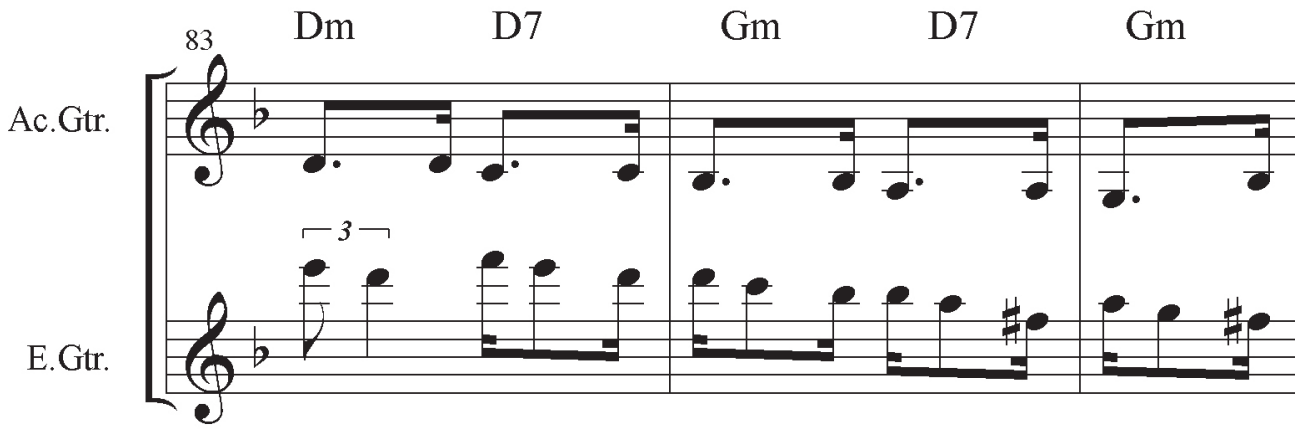

Ex.2 - Presença de ostinatos em sincopas em Odeon (Ernesto Nazareth) na gravação de Alemão e Zezo Ribeiro.

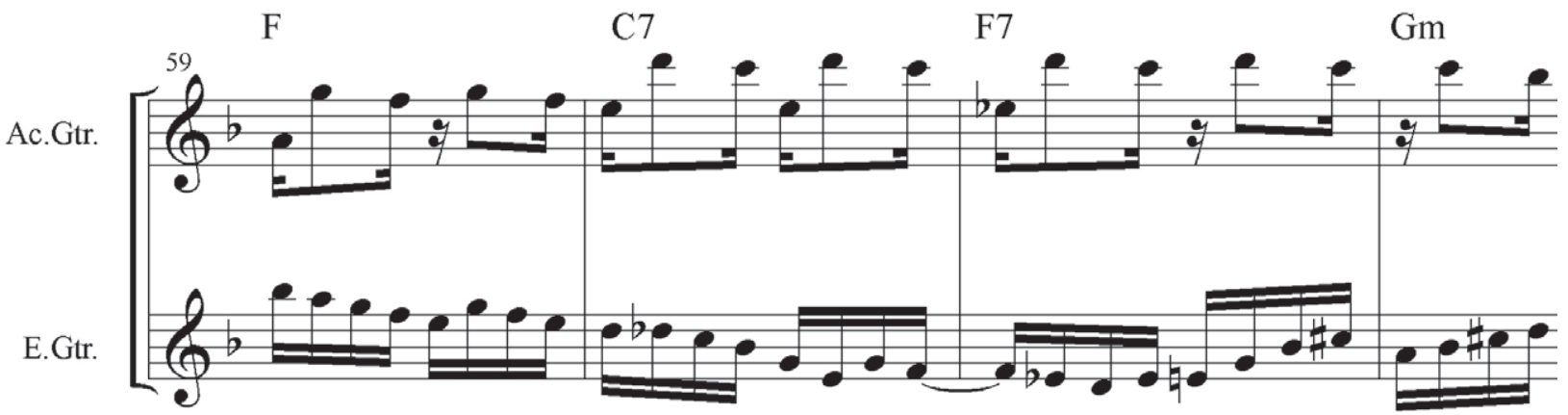

Ex.3 - Ocorrência de cromatismos em Odeon (Ernesto Nazareth) na gravação de Alemão e Zezo Ribeiro. 


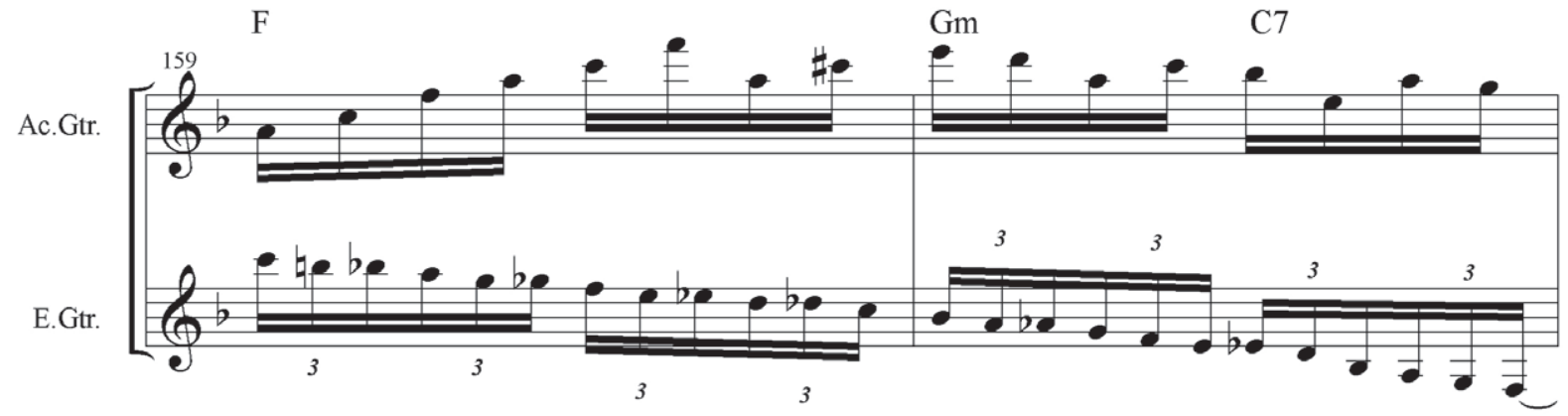

Ex.4 - Polirritmias de tercinas ou sextinas sobre semicolcheias em Odeon (Ernesto Nazareth) na gravação de Alemão e Zezo Ribeiro.

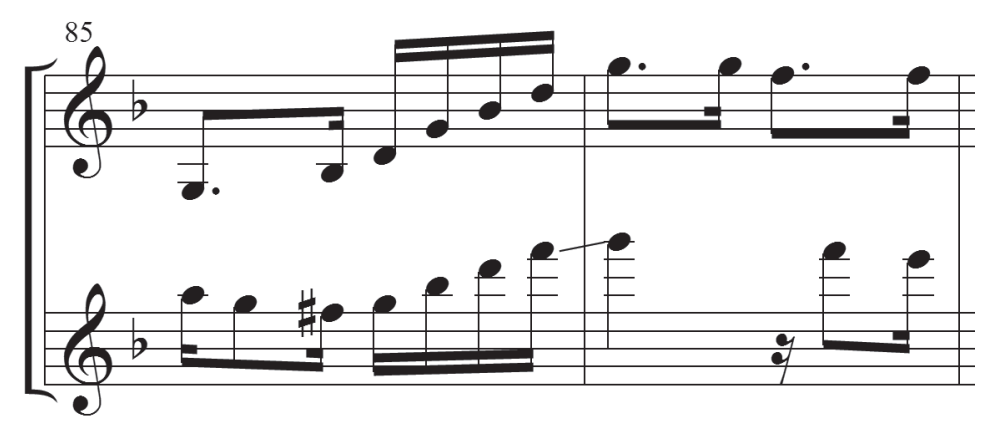

Ex.5 - Glissando na mesma corda (c.85-86): escrita idiomática na guitarra elétrica de Alemão em Odeon (Ernesto Nazareth) na gravação de Alemão e Zezo Ribeiro.

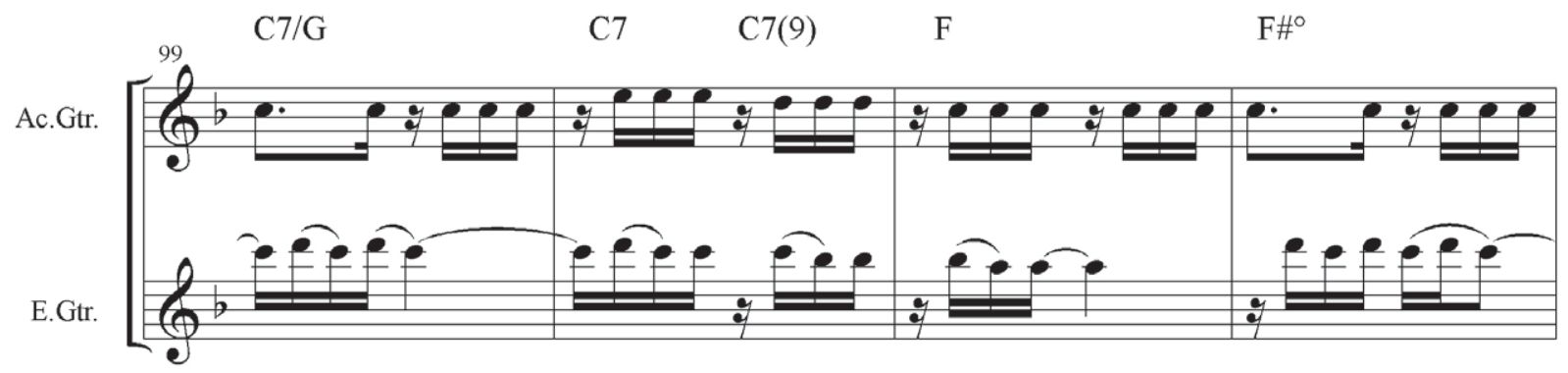

Ex.6 - Ligados ascendentes e descendentes (c.99-102) com articulação típica do bandolim no choro: escrita idiomática na guitarra elétrica de Alemão em Odeon (Ernesto Nazareth) na gravação de Alemão e Zezo Ribeiro. 


\section{4 - Considerações Finais}

A análise dos contrapontos improvisados na guitarra elétrica revelou alguns pontos importantes que caracterizam o processo de adaptação realizado por Alemão. A primeira impressão é que suas improvisações possuem pouca influência dos contrapontos de Pixinguinha, apenas na questão dos padrões melódicos e dos ostinatos (Exs.1, 2 e 4)

A base de seu contraponto está num desenvolvimento tonal e horizontal da melodia no sentido de construir uma linha melódica concisa. Para tanto, utiliza-se de notas cromáticas (Ex.3) que podem ser entendidas como uma complementação do ritmo da semicolcheia que sugerem uma maior fluência melódica ${ }^{4}$, e de figuras rítmicas como as tercinas (Ex.4), que criam uma sonoridade contrastante no compasso binário.

0 guitarrista utiliza-se de vários recursos idiomáticos do instrumento (Ex.5) como a ampla variedade e combinação de ligados ascendentes e descendentes, o uso de glissando na mesma corda, a sustentação de notas com duração de semínima e a ampla tessitura utilizada na improvisação. A ornamentação analisada abrange uma quantidade significativa dos recursos idiomáticos da guitarra elétrica e possui uma influência marcante dos idiomatismos do bandolim no choro.

0 estilo do guitarrista frente à "regras socialmente aceitas", que definem o gênero, parece sinalizar num sentido de inovações que não descaracterizam o gênero. A primeira delas é sua linha melódica improvisada, que está muito mais voltada para uma nova melodia do que a feitura de uma linha contrapontística com a melodia principal.

Um dos elementos mais expressivos que mostram o conhecimento da linguagem do choro é o ritmo e a ornamentação da improvisação. A análise musical se torna compatível com os depoimentos do maestro Gaya, e do próprio Alemão, ao apontarem que é possível tocar choro com qualquer instrumento. Para esses músicos, um dos elementos mais importante para interpretação do gênero é o conhecimento de suas estruturas fundamentais, que, no caso do guitarrista, mostra uma adaptação de uma linguagem carregada de brasilidade para a guitarra elétrica. Dessa maneira, o músico contribui para o desenvolvimento de uma linguagem brasileira para o instrumento, distanciando-o de sua origem norteamericana e reinventa sua presença dentro do universo da música popular brasileira.

\section{5 - Referências}

BAKER, David N. How to Play Bebop for All Instruments, The Bebop Scales and Other Scales in Common Use. Van Nuys, CA: Alfred Publishing, 1989.

CALDI, Alexandre. Contracantos de Pixinguinha: Contribuições históricas e analíticas para a caracterização do estilo. Rio de Janeiro, 2001. Dissertação de Mestrado. UNIRIO

CAZES, Henrique. Choro: do Quintal ao Municipal. 2ed. São Paulo: Ed. 34, 1999.

COOK, Richard. Master of Rhythm. ALEXANDER, Charles (org.). In: Masters of Jazz Guitar. London: Outline Press, 1999.

FABBRI, Franco. A Theory of Musical Genres: Two Applications. In: HORN, David e TAGG, Philip (org.). Popular Music Perspectives. Londres e Göteborg: IASPM, 1982.

FERNANDES, Dmtri C. A inteligência na música popular brasileira - a "autenticidade" no samba e no choro. São Paulo, 2010. Tese de Doutorado. FFLCH/USP.

MACHADO, Cacá. O Enigma do Homem Célebre: ambição e vocação de Ernesto Nazareth. São Paulo: Instituto Moreira Salles, 2007

NAVES, Santuza Cambraia. O Violão Azul - modernismo e música popular. RJ: Ed. FGV, 1998.

SARAIVA, Joana Martins. A invenção do sambajazz: discursos sobre a cena musical de Copacabana no final dos anos de 1950 e início dos anos 1960. Rio de Janeiro, 2007. Dissertação de Mestrado. PUC.

STOCKER, Olmir. Guitar Collection Pra Tocar- Vol. 2: Guitarra MPB. São Paulo: Íon Produções, 1999.

VISCONTI, Eduardo de L.. A guitarra elétrica na música popular brasileira: os estilos dos músicos José Menezes e Olmir Stocker. Campinas, 2010. Tese de Doutorado. IA/UNICAMP. . A guitarra brasileira de Heraldo do Monte. Campinas, 2005. Dissertação de Mestrado. IA/UNICAMP.

SĖVE, Mário. Vocabulário do choro. Rio de Janeiro: Lumiar, 1999.

SĖVE, Mário; GANC, David. Choro duetos vol.1. São Paulo: Irmãos Vitale, 2010. 


\section{Notas}

1 Um estudo mais aprofundado e abrangente sobre a guitarra elétrica no Brasil foi realizado num artigo de minha autoria denominado $A$ trajetória da guitarra elétrica no Brasil. Disponivel em:<http://www.musicosdobrasil.com.br/ensaio.jsf.>. Acesso em: 10 jan. 2012.

2 A classificação dessa música como choro foi feita em virtude desse termo condensar uma gama de gêneros urbanos. Para Cacá MACHADO (2007), a composição Odeon, como outras de Ernesto Nazareth, tiveram seus gêneros, muitas vezes, publicados com termos mais "aceitáveis" devidos aos preconceitos da elite carioca da época. Segundo consulta à partitura original, Odeon é caracterizada como um tango brasileiro. Disponível em: <http://www.ernestonazareth.com.br/pdfs/odeon.pdf.> Acesso em 25 mar. 2011. Nesse site ainda há a informação de que essa composição teve duas letras distintas em sua versão como canção, sendo a primeira elaborada por Hubaldo Maurício e a segunda por Vinicius de Moraes.

3 Cabe destacar também a importância do violonista Dino Sete Cordas no desenvolvimento de uma linguagem de acompanhamento com elementos contrapontísticos no choro. Como esses procedimentos não são exclusivamente de contraponto à melodia principal, optou-se pela referência de Pixinguinha.

4 No livro How to play Bepop, o músico e pesquisador David BAKER (1989) sistematizou a ocorrência de cromatismos presentes em escalas utilizadas nas improvisações do bebop. 0 autor expõe uma relação entre esses cromatismos, utilizados muitas vezes como complementação rítmica, com uma fluidez melódica dos improvisos.

Eduardo de Lima Visconti é Bacharel em Música Popular pela Universidade Estadual de Campinas (UNICAMP), Mestre e Doutor em Música (UNICAMP). Desenvolve pesquisa sobre seguintes temas: etnomusicologia, música popular, musicologia, ideologia, identidade cultural, análise musical, arranjo, improvisação, harmonia, guitarra e violão. Foi professor temporário de Guitarra Elétrica (I-VIII) e Prática de Conjunto (I-VIII) na graduação em música popular da UNICAMP no período de 2007 a 2012. Participou, em julho de 2012, como professor de guitarra/violão e improvisação na música popular no IX Festival de Música em Ibiapaba no Ceará. Atualmente, desenvolve pesquisa de Pós-Doutorado no Instituto de Estudos Brasileiros (IEB -USP) sobre arranjo e sonoridade no samba da década de 1970, com supervisão do prof. Dr. Walter Garcia. Tem se apresentado regularmente com seu trio e quarteto no Brasil e no exterior. 